\title{
Plasma membrane-generated ROS and their possible contribution to leaf cell growth of cucumber (Cucumis sativus) MSC16 mitochondrial mutant
}

\author{
Katarzyna Lukawska-Kuźma • Anna Podgórska • \\ Anna M. Rychter
}

Received: 20 June 2011/Revised: 5 September 2011/Accepted: 6 October 2011/Published online: 22 October 2011

(C) The Author(s) 2011. This article is published with open access at Springerlink.com

\begin{abstract}
Reactive oxygen species (ROS) generally regarded as harmful products of oxygenic metabolism causing oxidative stress and cell damage are also important for control and regulation of biological processes. ROS can be generated by various enzymatic activities and removed by an array of ROS-scavenging molecules in the cell. In plants, the generation of ROS initiated by the plasma membrane NADPH oxidase can be used for controlled polymer breakdown leading to cell wall loosening during extension growth. The mosaic (MSC16) mitochondrial mutant of cucumber (Cucumis sativus L.) has marked phenotypic changes, including a slower growth rate which partially may result from disturbed leaf carbon and energy metabolism and ROS/antioxidants equilibrium. Cytochemical localization of $\mathrm{H}_{2} \mathrm{O}_{2}$ in leaf cells showed lower total level of $\mathrm{H}_{2} \mathrm{O}_{2}$ particularly in the apoplast of MSC16 leaf cells as compared to WT. The activity of plasma membrane NADPH oxidase (EC 1.6.3.1) was about $30 \%$ lower in plasmalemma vesicles isolated from MSC16 leaf tissue as compared to WT. The total foliar ascorbate pool (reduced and oxidized) was about 35\% higher in MSC16 compared to WT leaves due to an increased content of the oxidized form. About 3\% of the whole-leaf ascorbate was localized in the apoplast but in MSC16 it was considerably more reduced. We conclude that the lower apoplastic ROS content caused by decreased activity of plasma membrane NADPH oxidase and lower amounts of $\mathrm{H}_{2} \mathrm{O}_{2}$ in the
\end{abstract}

Communicated by J.-H. Liu.

K. Łukawska-Kuźma · A. Podgórska · A. M. Rychter ( $\square)$ Institute of Experimental Plant Biology and Biotechnology, Faculty of Biology, University of Warsaw, Miecznikowa 1, 02-096 Warsaw, Poland

e-mail: arychter@biol.uw.edu.pl apoplast may also contribute to altered growth of the MSC16 cucumber mutant.

Keywords Apoplast - Cucumber mitochondrial mutant . NADPH oxidase $\cdot$ Plasma membrane $\cdot$ ROS

$\begin{array}{ll}\text { Abbreviations } \\ \text { ABA } & \text { Abscisic acid } \\ \text { AO } & \text { Ascorbate oxidase } \\ \text { AOX } & \text { Alternative oxidase } \\ \text { AsA } & \text { Ascorbic acid } \\ \text { DHA } & \text { Dehydroascorbate } \\ \text { DAB } & \text { 3,3-Diaminobenzidine } \\ \text { DPI } & \text { Diphenyleneiodonium } \\ \text { DTT } & \text { Dithiothreitol } \\ \text { ETC } & \text { Electron transport chain } \\ \text { EWF } & \text { External washing fluid } \\ \text { FW } & \text { Fresh weight } \\ \text { MDHA } & \text { Monodehydroascorbate } \\ \text { MSC16 } & \text { Mosaic cucumber } \\ \text { PAR } & \text { Photosynthetically active radiation } \\ \text { PM } & \text { Plasma membrane } \\ \text { PVPP } & \text { Polyvinylpolypyrrolidone } \\ \text { ROS } & \text { Reactive oxygen species } \\ \text { SOD } & \text { Superoxide dismutase } \\ \text { WT } & \text { Wild type }\end{array}$

\section{Introduction}

Reactive oxygen species (ROS) are generally regarded as harmful products of oxygenic metabolism causing oxidative stress and cell damage. However, in the past years it became apparent that ROS, especially hydrogen peroxide, 
have a major role in cellular signalling pathways across a wide range of organisms, including plants (Foyer and Noctor 2009). ROS can be generated in plants via the mitochondrial or photosynthetic electron transport chain (ETC), by peroxisomes or can be synthesized in the apoplast by a variety of dedicated enzymes, such as peroxidases and NADPH oxidases (Foyer and Noctor 2009). Once produced, ROS can take part in signalling, although these events are modulated by antioxidants in or around the cell. Some of the key events in plants which are controlled by ROS include stomatal closure (Pei et al. 2000), root growth (Foreman et al. 2003), programmed cell death and the hypersensitive response (Desican et al. 1998).

The plasmalemma of plant cells produces bursts of $\mathrm{H}_{2} \mathrm{O}_{2}$ in response to biotic (Vanacker et al. 1998) and abiotic stimuli (Laloi et al. 2004; Piotrovskii et al. 2011). The mechanisms involved in regulation of these bursts are largely unknown but it is speculated that ROS such as $\mathrm{H}_{2} \mathrm{O}_{2}$ can also serve as regulators of the redox state of cells allowing controlled oxidation of cell compartments (Foyer and Noctor 2009). In plants the production of ROS initiated by the plasma membrane NADPH oxidase can be used for controlled polymer breakdown leading to wall loosening during extension growth (Schopfer and Liszkay 2006). The redox signals are also integral to the transduction sequences by which changes in the environment modify metabolism and gene transcription (Foyer and Noctor 2009).

ROS perception, signalling and ROS-mediated protein modifications are controlled and modulated by an array of antioxidants. In plants ascorbate (AsA) plays a key role in defence against oxidative stress and is particularly abundant in photosynthetic tissues (Foyer and Noctor 2009). Over $90 \%$ of the AsA is localized in the cytoplasm, but a small portion is exported to the apoplast, where it is present in millimolar concentrations. It is by far the most abundant low-molecular-weight antioxidant in the apoplast (Vanacker et al. 1998). Other antioxidants, such as GSH, are either absent from the apoplast or present in low concentrations (Vanacker et al. 1998). In the apoplast AsA is oxidized to monodehydroascorbate (MDHA) by ascorbate oxidase (AO). MDHA is an unstable radical and rapidly disproportionates to yield dehydroascorbate (DHA) and AsA. DHA is then transported into the cytosol through the plasma membrane by a specific carrier that preferentially translocates the oxidized form in exchange for the reduced form, ensuring the continuous flux of reducing power to the cell wall (Horemans et al. 2000). AsA is not only an important antioxidant but also a cofactor of many enzymes (Smirnoff and Wheeler 2000) and a regulator of cell division and growth (Kerk and Feldman 1995). Moreover, AsA is a signal-transducing molecule in plants (Pastori et al. 2003; Foyer and Noctor 2009). Antioxidant defence of the apoplast received lots of attention when the importance of this compartment in cell growth, plant defence, signal transduction and mineral nutrition has become apparent (Foyer and Noctor 2005).

One of the enzymes involved in AsA metabolism, with no clear biological function described to date, is the apoplastic ascorbate oxidase. However, it is believed that AO plays a role in cell elongation because of its extracellular localization and its high activity in rapidly expanding tissues (Kato and Esaka 1999). Several mechanisms whereby AO controls cell growth have been proposed (Smirnoff 2000). MDHA generated from AsA by AO in the apoplast stimulates cell growth through enhanced vacuolization and ion uptake caused by depolarization of the plasma membrane. Moreover, DHA is considered to be responsible for cell enlargement by promoting cell wall loosening (Lin and Varner 1991). AsA is believed to be the most important antioxidant in the apoplast of leaves and stems and that is why its destruction via AO may be important in facilitating cell expansion. Pignocchi and Foyer (2003) showed that expression of AO is regulated by light and by growthmodulating plant hormones. Moreover, they have demonstrated that in transformed tobacco plants enhanced apoplastic AO activity oxidizes the apoplastic AsA pool resulting in stimulation of growth (Pignocchi and Foyer 2003). Taken together, all published data provide the evidence that AsA and AO in the apoplast are key players in both cell division and cell expansion. ROS level, abundance and redox state of the apoplastic ascorbate pool, as well as the enzymes involved in AsA production and turnover play a role in growth control of plants. Thus, plant growth is the outcome of various mechanisms of regulation, signalling and their crosstalk.

The mosaic (MSC16) mutant of cucumber was produced from in vitro cultures by regeneration of the original cucumber B cell line (Malepszy et al. 1996). Crossing the MSC16 mutant with line B showed that the MSC16 phenotype is not associated with either the nuclear or the chloroplast genome (Malepszy et al. 1996). Plants with the MSC16 phenotype have a JLV5 deletion in a non-coding region of the mitochondrial genome, although the precise nature of this mutation remains unknown (Bartoszewski et al. 2004). The MSC16 line has marked phenotypic changes, including a slower growth rate and a leaf mosaic pattern with chlorotic patches (Malepszy et al. 1996). The mitochondrial genome rearrangement in cucumber MSC16 results in a decreased leaf ATP concentration, changes in nucleotides distribution (Szal et al. 2008) and changes in respiratory chain activity, including lower Complex I capacity, increased activities of external NADH dehydrogenases (NDex), higher alternative oxidase (AOX) capacity and protein level (Juszczuk et al. 2007; Juszczuk and Rychter 2009). Cytochemical detection revealed an increased abundance of $\mathrm{H}_{2} \mathrm{O}_{2}$ in the mitochondrial 
membrane and decreased $\mathrm{H}_{2} \mathrm{O}_{2}$ content in the apoplast of mesophyll cells in MSC16 leaves (Szal et al. 2009). The mitochondrial mutation also resulted in changes in the antioxidant defence system (Szal et al. 2009). However, these changes in MSC16 metabolism only partially explain its phenotype, especially the altered growth rate.

The present study was undertaken to elucidate the role of the apoplast in formation of the MSC16 phenotype. We showed that a lower content of apoplastic ROS caused by decreased activity of the plasma membrane NADPH oxidase may contribute to altered growth and development of MSC16 cucumber mutant. This can be a result of changes in whole cell energy and redox state caused by impairment of mitochondrial function.

\section{Materials and methods}

Plant material and growth conditions

Cucumber seeds (Cucumis sativus L. cv. Borszczagowski) of wild type (WT) or MSC16 mutant were germinated on moist filter paper and 3-day-old seedlings were transferred to boxes with complete Knop medium (Rychter and Mikulska 1990). The nutrient solution was supplemented every day and changed every 4 days. Plants were grown under $16 \mathrm{~h}$ photoperiod at $150 \mu \mathrm{mol} \mathrm{m} \mathrm{m}^{-2} \mathrm{~s}^{-1}$ PAR (daylight and warm white 1:1, LF-40W, Piła, Poland), day/ night temperature of $24^{\circ} \mathrm{C} / 20^{\circ} \mathrm{C}$ and $60 / 70 \%$ relative humidity. Leaves from the same developmental stage from about 2-week-old WT and 3-week-old MSC16 plants were taken for analysis.

In vivo detection of $\mathrm{H}_{2} \mathrm{O}_{2}$ in plants

$\mathrm{H}_{2} \mathrm{O}_{2}$ was visually detected in the leaves of plants by using 3,3-diaminobenzidine (DAB) as substrate. Plants were excised at the base of leaves with a razor blade and supplied with a $1 \mathrm{mg} \mathrm{mL}^{-1}$ solution of DAB, $\mathrm{pH} \mathrm{3.8,} \mathrm{for} 8 \mathrm{~h}$ under light at $24^{\circ} \mathrm{C}$ as described by Orozco-Cárdenas and Ryan (1999).

Cytochemical localization of hydrogen peroxide in leaf mesophyll cells

Cellular $\mathrm{H}_{2} \mathrm{O}_{2}$ localization was determined cytochemically from cerium perhydroxide deposition after reaction of $\mathrm{CeCl}_{3}$ with endogenous $\mathrm{H}_{2} \mathrm{O}_{2}$ (Bestwick et al. 1997). Positive staining was detected in electron micrographs as the formation of electron-dense deposits. For determination of NADPH oxidase participation in apoplastic ROS production leaf fragments were previously incubated for $1 \mathrm{~h}$ with $8 \mu \mathrm{M}$ DPI. Tissues were then fixed in $2 \%$ glutaraldehyde in HEPES buffer ( $\mathrm{pH} 7.3)$ at room temperature for $2 \mathrm{~h}$. After fixation they were washed three times for $10 \mathrm{~min}$ in $0.05 \mathrm{M}$ HEPES buffer at room temperature and post-fixed for $90 \mathrm{~min}$ in $1 \%$ osmium tetraoxide. After dehydration in an ethanol series $(50,70,96$ and 100\%) samples were embedded in Epon 812 resin and polymerized. Sections were made and examined with transmission electron microscope (Leo 912AB). Photographs of the semi-thin sections were taken.

\section{Preparation of PM vesicles}

Plasma membrane vesicles were prepared strictly at $4{ }^{\circ} \mathrm{C}$ (Palmgren 1990). Briefly, whole leaves (50-90 g FW) of MSC16 or WT plants were ground in the presence of $0.6 \%$ (w/v) polyvinylpolypyrrolidone (PVPP) with a homogenizing buffer $50 \mathrm{mM}$ Mops-1,3-bis(tris[hydroxymethyl]methylamino) propane (BTP) $(\mathrm{pH}$ 7.0) with $330 \mathrm{mM}$ sucrose, $5 \mathrm{mM}$ EDTA, $5 \mathrm{mM}$ dithiothreitol (DTT), $1 \mathrm{mM}$ phenylmethylsulfonyl fluoride (PMSF), $5 \mathrm{mM}$ ascorbate, $0.2 \%(\mathrm{w} / \mathrm{v})$ bovine serum albumin and $0.2 \%(\mathrm{w} / \mathrm{v})$ casein. The homogenate was filtered through nylon mesh $(240 \mu \mathrm{m})$ and centrifuged $(10,000 \times g, 15 \mathrm{~min})$. The supernatant was centrifuged $(30,000 \times g, 55 \mathrm{~min})$, and the resulting precipitate was resuspended with a glass homogenizer in suspension buffer consisting of $5 \mathrm{mM}$ K-phosphate (pH 7.8) with $330 \mathrm{mM}$ sucrose and $2 \mathrm{mM}$ DTT. The homogenate was loaded on a $24 \mathrm{~g}$ two-phase system containing 6.7\% (w/w) Dextran T500, 6.7\% (w/w) polyethylene glycol 4000, $330 \mathrm{mM}$ sucrose, $5 \mathrm{mM}$ K-phosphate ( $\mathrm{pH} 7.8)$ and $4 \mathrm{mM} \mathrm{KCl}$. After the batch procedure, the resulting upper phase was mixed with a dilution buffer that consisted of $330 \mathrm{mM}$ sucrose, $5 \mathrm{mM}$ Na-phosphate ( $\mathrm{pH} 7.8)$, and centrifuged $(120,000 \times g$, $45 \mathrm{~min})$. This method results in apoplastic-side-out vesicles. To ensure substrate accessibility for NADPH oxidase measurements, the vesicles were turned cytoplasmic-sideout by repeated freezing in liquid nitrogen and thawing in room temperature. In our earlier experiments we found similar effect of both Brij 58 and freezing-thawing technique. The cytoplasmic-side-out PM vesicles were used immediately, or stored otherwise at $-80^{\circ} \mathrm{C}$ until further analysis.

\section{Determination of $\mathrm{H}^{+}$ATPase activity in PM vesicles}

ATPase (EC 3.6.3.6) activity was determined simultaneously with proton pumping (Palmgren and Sommarin 1989). The assay medium consisted of $10 \mathrm{mM}$ Mops-BTP (pH 7.0), $2 \mathrm{mM}$ ATP, $4 \mathrm{mM} \mathrm{MgCl} 2,140 \mathrm{mM} \mathrm{KCl}, 1 \mathrm{mM}$ EDTA, $1 \mathrm{mM}$ DTT, $20 \mu \mathrm{M}$ acridine orange, $0.25 \mathrm{mM}$ $\mathrm{NADH}, 1 \mathrm{mM}$ PEP, $50 \mu \mathrm{g} \mathrm{mL}^{-1}$ pyruvate kinase (Roche, 85884429), $25 \mu \mathrm{g} \mathrm{mL}^{-1}$ lactate dehydrogenase (Sigma, 
$\mathrm{L}-2518$ ), and $50 \mu \mathrm{g} \mathrm{mL}^{-1}$ plasma membrane protein in a total volume of $1 \mathrm{~mL}$. Stock solutions of ATP, EDTA, $\mathrm{BSA}$, and PEP, all pH 7.0 with BTP, were stored in frozen vials and thawed just prior to use. A mixture containing Mops-BTP, ATP, $\mathrm{KCl}$, EDTA, DTT, BSA, and acridine orange was equilibrated at $20^{\circ} \mathrm{C}$ and a portion of $800 \mu \mathrm{L}$ was transferred to a disposable $1-\mathrm{mL}$ cuvette, $1 \mathrm{~cm}$ light path. Then, $5 \mu \mathrm{L}$ of membrane suspension was added, followed by $70 \mu \mathrm{L}$ of a freshly prepared solution of NADH mixed with PEP, $30 \mu \mathrm{L}$ of a mixture of pyruvate kinase and lactate dehydrogenase. After incubation for $5 \mathrm{~min}$, automatic recording at 15 -s intervals at 340 and $495 \mathrm{~nm}$ was initiated using a spectrophotometer (Shimadzu UV-160A) that can automatically switch between the two wavelengths. Twenty microliters of $272 \mathrm{mM} \mathrm{MgCl} 2$ were added to start the reaction and mixed into the assay solution by stirring for a few seconds with the tip of the pipette. In this assay the rate of ATP hydrolysis was quantified from the rate of NADH oxidation measured at $340 \mathrm{~nm}$ after $30 \mathrm{~s}$. Proton uptake into the vesicles was monitored simultaneously as the absorbance decrease at $495 \mathrm{~nm}$ of the $\Delta \mathrm{pH}$ probe acridine orange. ATPase activity was measured in absence and presence of $100 \mathrm{mM} \mathrm{Na} \mathrm{VO}_{4}$, a specific inhibitor of plasma membrane $\mathrm{H}^{+}$ATPase activity. Proton pumping was determined from the initial slope of acridine orange absorbance quenching.

\section{Determination of cytochrome $c$ oxidase activity}

Cytochrome $c$ oxidase (COX, EC 1.9.3.1) activity was measured according to Wigge and Gardeström (1987) in a medium consisting of $0.45 \mathrm{M}$ mannitol, $10 \mathrm{mM}$ phosphate buffer (pH 7.2), $100 \mathrm{mM} \mathrm{KCl}, 50 \mu \mathrm{M}$ cytochrome $c$ (reduced with a few crystals of sodium dithionite) and $20 \mu \mathrm{g}$ plasma membrane protein in the presence of $0.02 \%$ (w/v) Triton X-100.

\section{Protein gel blot analyses of $\mathrm{H}^{+}$ATPase}

Protein gel blot analyses were performed using plasma membrane vesicles isolated from MSC16 or WT leaves. Samples of 5, 10 and $20 \mu \mathrm{g}$ protein per lane, were separated by SDS-PAGE (10\% polyacrylamide) according to a standard protocol. The polypeptides were electroblotted onto nitrocellulose membrane and probed with primary antibody overnight at $4^{\circ} \mathrm{C}$ and $30 \mathrm{~min}$ RT. Plasma membrane $\mathrm{H}^{+}$ ATPase (anti- $\mathrm{H}^{+}$ATPase, Agrisera) antibodies were used as primary antibodies at a dilution of 1/1,000. Anti-rabbit antibodies conjugated to horseradish peroxidase (BIO-RAD) were used as secondary antibodies at a dilution of 1/35,000. Visualization was performed with a chemiluminescent reagent system. Blot was quantified by densitometry using Quantity One 4.6.2 software (Bio-Rad Ltd. USA).
Determination of NADPH oxidase activity

Superoxide anion production by plasma membrane-bound NADPH oxidase (EC 1.6.3.1) was determined using a lucigenin-enhanced chemiluminescence method (Chen et al. 2005). The reaction test tube contained $50 \mathrm{mM}$ phosphate buffer (pH 7.0), $150 \mathrm{mM}$ sucrose, $1 \mathrm{mM}$ EGTA, $5 \mathrm{mM}$ lucigenin and plasma membrane vesicles (about $100 \mu \mathrm{g}$ of protein). The reaction was started by addition of NADPH to a final concentration of $0.1 \mathrm{mM}$. Chemiluminometric measurements were performed using Thriatler 425-014 luminometer (Hidex Ltd. Turku, Finland).

\section{Determination of ascorbate oxidase activity}

Ascorbate oxidase (EC 1.10.3.3) activity was determined according to Nanasato et al. (2005) with minor modifications. The fourth leaf of WT or MSC16 plants $(0.5 \mathrm{~g} \mathrm{FW})$ was ground in liquid nitrogen and homogenized with $1 \mathrm{~mL}$ of $50 \mathrm{mM}$ K-phosphate buffer (pH 7.0), $1 \mathrm{M} \mathrm{KCl}, 10 \mathrm{mM}$ 2-mercaptoethanol, $1.5 \%(\mathrm{w} / \mathrm{v})$ PVPP and $1 \mathrm{mM}$ PMSF. The mixture was allowed to stand on ice for $20 \mathrm{~min}$, vortexed every $3 \mathrm{~min}$ and centrifuged at $15,000 \times \mathrm{g}$ for $20 \mathrm{~min}$ at $4^{\circ} \mathrm{C}$. The resulting supernatant was used immediately for the enzyme assay. Ascorbate oxidase activity was determined by measuring the decrease in absorbance at $290 \mathrm{~nm}$ due to AsA oxidation in the reaction mixture containing $50 \mathrm{mM}$ K-phosphate (pH 5.3), $0.5 \mathrm{mM}$ AsA and $20 \mu \mathrm{L}$ of leaf extract. Oxidation of AsA was monitored at $25^{\circ} \mathrm{C}$ $\left(\varepsilon=2.8 \mathrm{mM}^{-1} \mathrm{~cm}^{-1}\right)$.

\section{Extraction of soluble apoplastic components}

Soluble apoplastic metabolites were determined in external washing fluid (EWF) by a method similar to that described by Polle et al. (1990). Freshly cut leaves (5 g) were washed three times with distilled water, placed in aluminium foil dishes containing $50 \mathrm{~mL}$ of infiltration solution consisting of $50 \mathrm{mM}$ acetate buffer $(\mathrm{pH} 4.5), 100 \mathrm{mM} \mathrm{KCl}$, and $2 \mathrm{mM} \mathrm{CaCl}$. To ensure immersion, a second perforated aluminium dish was placed on top of the leaves in the infiltration solution. The infiltration dishes were placed in a vacuum desiccator and the leaves were infiltrated for 5-7 periods of $5 \mathrm{~min}$ at about $-70 \mathrm{kPa}$. Then they were blotted gently, loaded into a perforated centrifuge tube $(5 \mathrm{~mL})$, and placed in a Falcon tube $(14 \mathrm{~mL})$. EWF was recovered by centrifugation $\left(10 \mathrm{~min}, 2,900 \times g, 4^{\circ} \mathrm{C}\right)$, directly in Falcon tubes containing $100 \mathrm{~mL}$ of $0.1 \mathrm{M} \mathrm{HClO}_{4}$ to immediately stop metabolism. Before analysis, sufficient $\mathrm{K}_{2} \mathrm{CO}_{3}(5 \mathrm{M})$ was added to each sample of EWF to adjust the $\mathrm{pH}$ from 4.0 to 5.0. Between 1.1 and $1.2 \mathrm{~mL}$ of EWF was obtained from $5 \mathrm{~g}$ of leaves (FW). EWF was used immediately after 
isolation for ascorbate measurements, in all cases the samples were kept at $4^{\circ} \mathrm{C}$ until assay. Contamination by cytoplasmic enzymes of the EWF fraction, monitored by the activity of glucose-6-phosphate dehydrogenase (RosBarceló et al. 2002) was always less than $0.2 \%$.

\section{Ascorbate determination}

Ascorbate was assayed according to the method described by Kampfenkel et al. (1995). In order to measure total ascorbate content, DHA was reduced with DTT. DHA content was calculated from the difference between the concentration of total and reduced ascorbate.

\section{Cell wall preparation}

Cell walls from leaves of WT and MSC16 plants were prepared using a method of Wu et al. (1998) modified by Solecka et al. (2008). Fresh leaf tissues were homogenized in 0.05 M HEPES buffer ( $\mathrm{pH}$ 6.5), containing a mixture of protease inhibitors (PMSF, aprotinin, bestatin, pepstatin A and leupeptine, $1 \mathrm{mM}$ each), filtered through Miracloth and washed several times with cold water. Cell wall proteins were extracted from crude cell wall preparation with HEPES buffer containing $1 \mathrm{M} \mathrm{NaCl}$ for $12 \mathrm{~h}$ at $4^{\circ} \mathrm{C}$ (Solecka et al. 2008). Dry matter of crude cell wall preparations after air drying was determined by weighing.

Determination of cell wall guaiacol peroxidase activity

POX (EC 1.11.1.7) activity was analysed in $44 \mathrm{mM}$ acetate buffer (pH 5.0) containing $10 \mathrm{mM}$ guaiacol and $2.2 \mathrm{mM}$ $\mathrm{H}_{2} \mathrm{O}_{2}$ at room temperature as described by Van den Berg and Van Huystee (1984). The increase in absorbance at $470 \mathrm{~nm}$ was recorded for $3 \mathrm{~min}$ after $1 \mathrm{mM} \mathrm{H}_{2} \mathrm{O}_{2}$ addition. Enzyme activity was expressed as the average of three replicates in units $\mathrm{mg}^{-1}$ protein $^{-1}$.

\section{Protein determination}

Protein content was measured according to the method of Bradford (1976) with bovine serum albumin (BSA) as a standard.

\section{Statistical analysis}

The results presented are the mean values with standard deviations of $n(n=3-11)$ measurements from 3-5 independent plant cultures. Significance of the results compared to the control was tested using Student's $t$ test. Asterisk indicates significant differences $(P \leq 0.05)$.

\section{Results}

It was reported earlier (Malepszy et al. 1996; Juszczuk et al. 2007) that MSC16 mutant plants have a considerably slower growth rate and deformed leaves comparing to WT. Cross section of leaves showed that in the mesophyll tissue of MSC16 the area of one cell is often $50-100 \%$ greater than of comparable WT leaf cells (Fig. 1). DAB staining of the whole leaves showed less dark brown spots in MSC16 leaves as compared to WT (Fig. 2) indicating lower $\mathrm{H}_{2} \mathrm{O}_{2}$ level in MSC16 leaves. Low $\mathrm{H}_{2} \mathrm{O}_{2}$ level was found to be mainly located at the cell wall and/or attached to the plasma membrane (Szal et al. 2009). Incubation of leaf tissue with DPI, a potent inhibitor of NADPH oxidase, strongly reduced the production and accumulation of $\mathrm{H}_{2} \mathrm{O}_{2}$ in the apoplast of both WT and MSC16 cells (Fig. 3).

NADPH oxidase is located in the plasma membrane, substrate site facing the inner side of plasmalemma (Sagi and
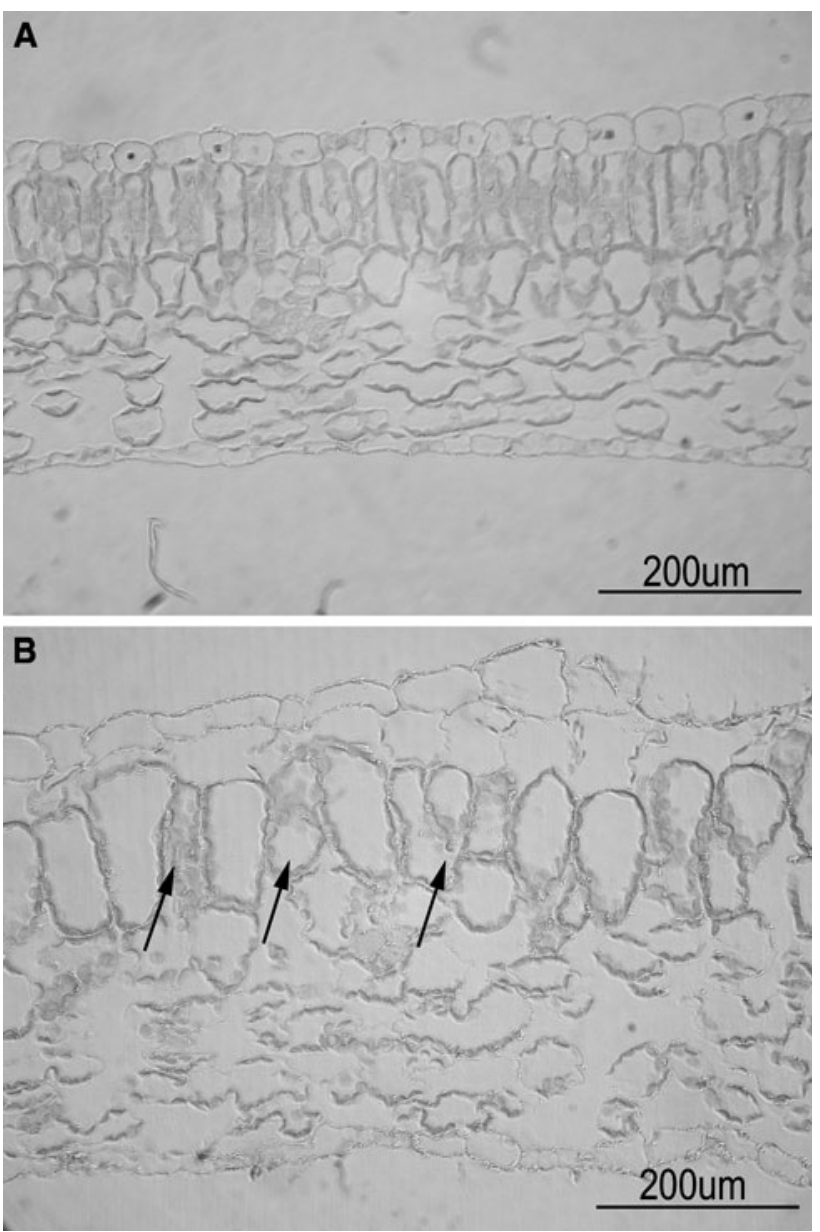

Fig. 1 Cross-section through leaf blades of WT (a) and MSC16 (b) plants. MSC16 plants have thicker leaf blades with a disturbed structure of palisade and spongy mesophyll. Palisade mesophyll cells of MSC16 plants are bigger, often with irregular shapes (black arrows) 


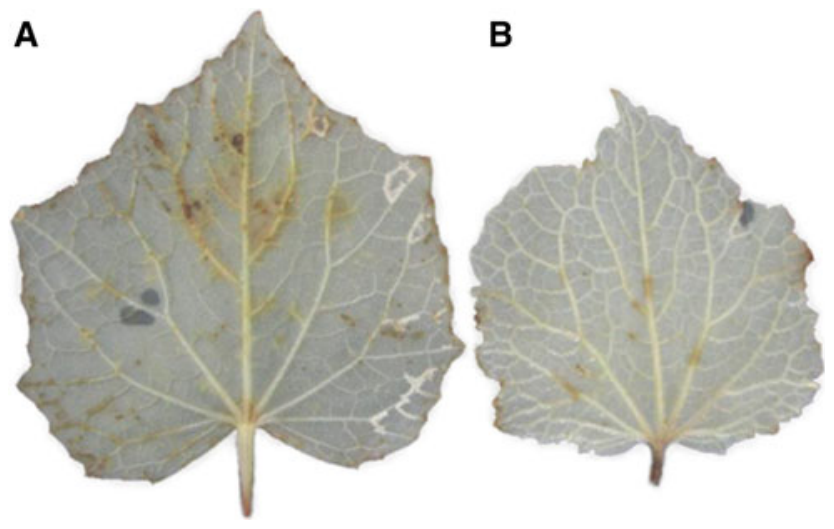

Fig. 2 Localization of $\mathrm{H}_{2} \mathrm{O}_{2}$ in leaves of WT (a) and MSC16 (b) plants by DAB staining. Leaves from 2 (WT) or 3 (MSC16) weeks old plants of the same developmental stage were cut and stained with DAB solution

Fluhr 2006). To compare the activity of NADPH oxidase we isolated plasma membrane vesicles from leaves of WT and MSC16 plants. The purity of PM vesicles was validated by measuring the activity of enzymes characteristic of other cell compartments. Low activity of the mitochondrial membrane marker cytochrome $c$ oxidase was detected (about $30 \mathrm{nmol} \mathrm{min}{ }^{-1} \mathrm{mg}^{-1}$ protein). The contamination with tonoplast was checked as ATPase activity, measured in the presence and absence of an inhibitor. Vanadate, which is a specific inhibitor of PM ATPase activity (Palmgren and Sommarin 1989) inhibited enzyme activity by more than $60 \%$. To check if the plasma membrane vesicles isolated from both MSC16 and WT leaves had comparable protein content, $\mathrm{H}^{+}$ATPase protein level was measured.
Arabidopsis $\mathrm{PM} \mathrm{H}^{+}$ATPase antibody detected a single band at approximately $95 \mathrm{kDa}$ in $\mathrm{PM}$ vesicle proteins, showing a comparable protein amount in MSC16 and WT PM vesicles as estimated by densitometric measurements (Fig. 4). In PM vesicles isolated from MSC16 leaves NADPH oxidase activity was about $30 \%$ lower compared to PM vesicles isolated from WT leaves (Fig. 4).

Cell wall peroxidases are also responsible for apoplastic ROS production (Wojtaszek 1997; Ros-Barceló 1998) and, similarly to the plasma membrane NADPH oxidase, their activity could also be inhibited by DPI. To determine if peroxidase activity may contribute to the decreased $\mathrm{H}_{2} \mathrm{O}_{2}$ content we have isolated cell walls from WT and MSC16 plants and found that guaiacol peroxidase activity was low and comparable in both plants (0.7-0.8 $\mathrm{U} \mathrm{min}^{-1} \mathrm{mg}^{-1}$ protein).

AsA is an important component of the complex network of control and interactions that regulates growth. Therefore, the abundance and redox state of the major soluble antioxidant-ascorbate was estimated in soluble apoplastic components isolated from WT and MSC16 leaves and compared to the values found in leaf homogenates. Apoplastic ascorbate (AsA + DHA) accounts only for 2-3\% of total ascorbate measured in homogenates in MSC16 or WT leaves (Szal et al. 2009). Total ascorbate concentration was about $14 \%$ higher in MSC16 EWF extracts and the reduced form (AsA) was substantially more abundant than in WT EWF extracts (Fig. 5).

Ascorbate oxidase (AO), the enzyme responsible for ascorbate metabolism in the apoplast is present solely in the apoplast; therefore, its activity was detected in wholeleaf extracts. The AO activity measured as the oxidation of
Fig. 3 Cellular localization of $\mathrm{H}_{2} \mathrm{O}_{2}$ in mesophyll cells of cucumber MSC16 (a, b) and WT $(\mathbf{c}, \mathbf{d})$ leaf blades with $\mathrm{CeCl}_{3}$-staining and transmission electron microscopy before and after DPI treatment. After DPI treatment no $\mathrm{H}_{2} \mathrm{O}_{2}$ accumulation was detected in the apoplast of MSC16 (b) and only a little in the apoplast of WT (d); $C h$ chloroplast, $C W$ cell wall, $M$ mitochondrion, $P$ peroxisome
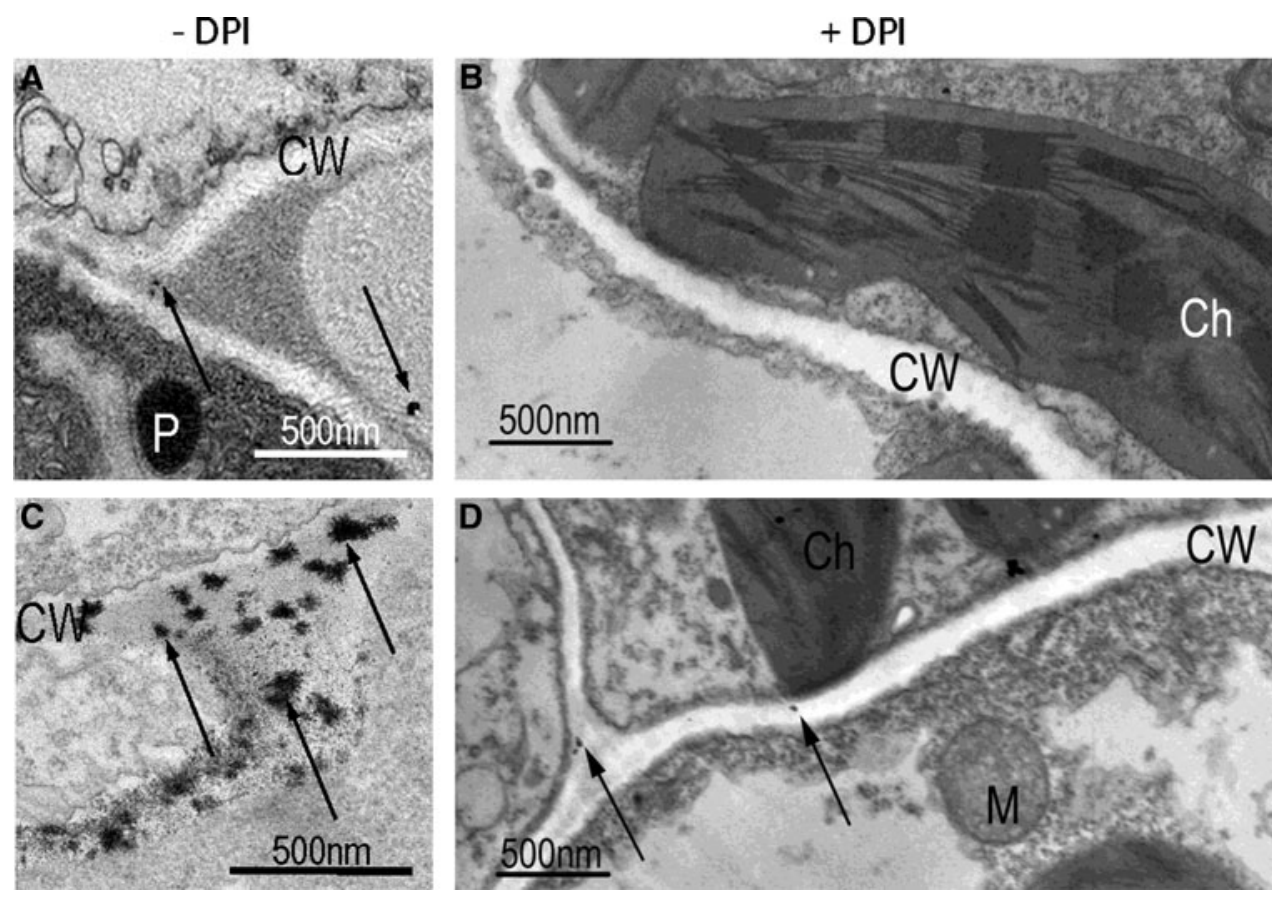


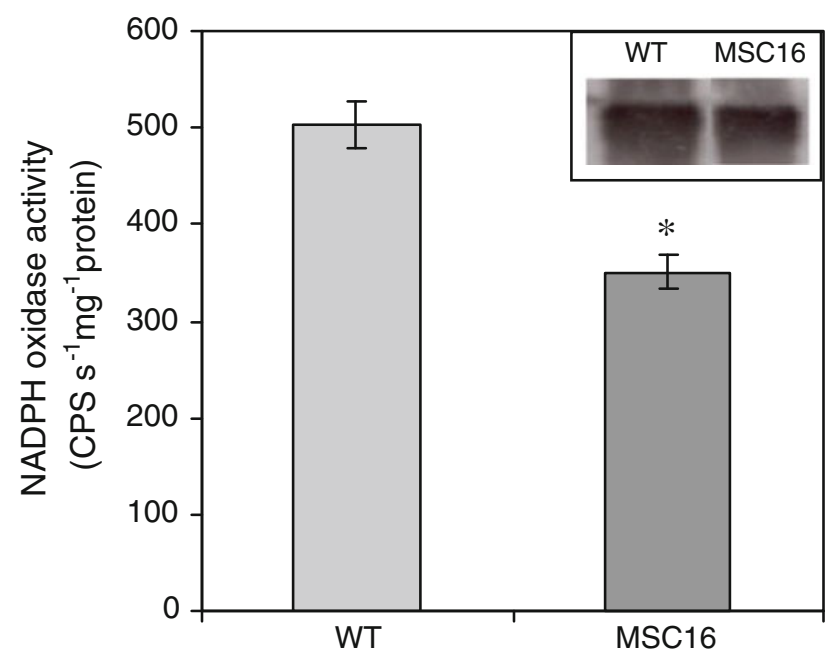

Fig. 4 NADPH oxidase activity in the plasma membrane vesicles isolated from WT and MSC16 leaves, measured using a lucigeninenhanced chemiluminescence method. Each value represents the mean $\pm \mathrm{SD}$ of five independent measurements. In the upper right corner protein determination of plasma membrane $\mathrm{H}^{+}$ATPase from $\mathrm{PM}$ vesicles was given as a control. Eight micrograms of protein was loaded per lane, separated by SDS-PAGE, immunoblotted and visualized by chemiluminescence

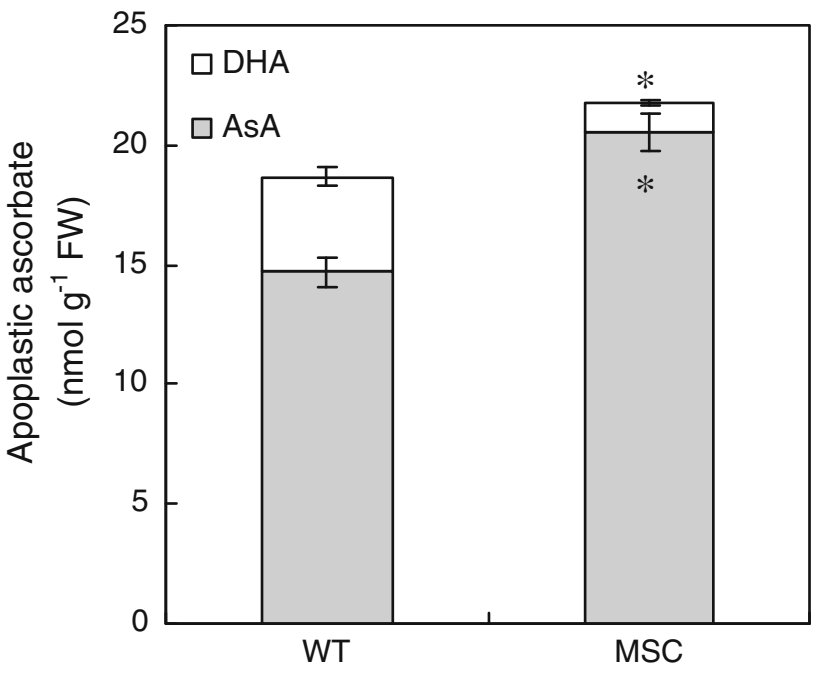

Fig. 5 Ascorbate concentration in leaf soluble apoplastic components from WT and MSC16 plants. Total $(A s A+D H A)$ and reduced $(A s A)$ ascorbate were determined separately using a colorimetric method. Values are means $\pm \mathrm{SD}$ from three replicates. Marked significance relates to the level of both AsA and DHA

AsA to DHA was about 40\% higher in MSC16 leaf extracts compared to WT (Fig. 6).

\section{Discussion}

In addition to earlier described effects of mitochondrial mutation on MSC16 leaf carbon and energy metabolism

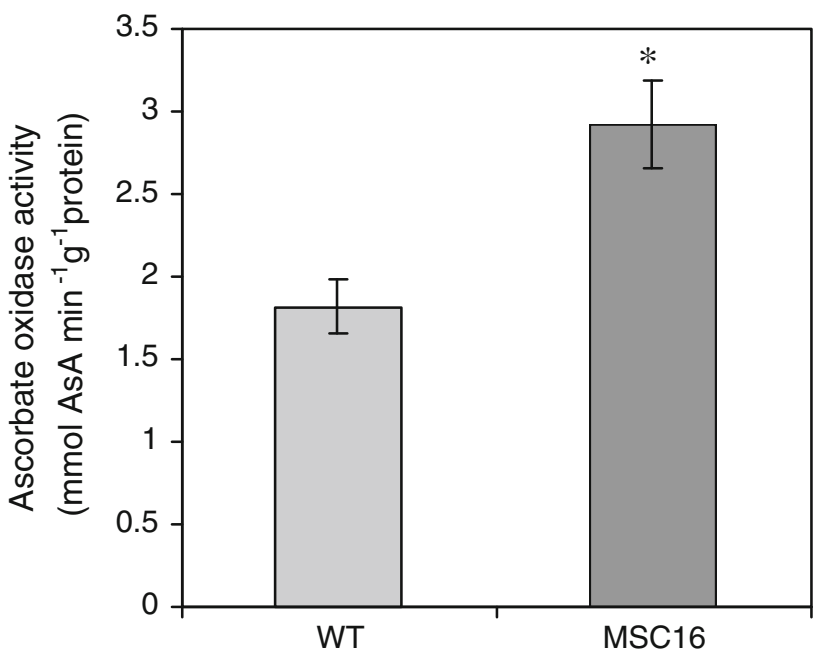

Fig. 6 Ascorbate oxidase activity in leaf samples of WT and MSC16 plants. Each value represents the mean $\pm \mathrm{SD}$ of three independent measurements

which may affect growth (Juszczuk et al. 2007; Szal et al. 2009, 2010), our data indicate also the possible involvement of apoplastic ROS. ROS level in the apoplast is the result of the activities of plasma membrane-located NADPH oxidases (Low and Merida 1996; Lamb and Dixon 1997) and cell wall-located peroxidases (Wojtaszek 1997). Diphenyleneiodonium (DPI) is known to be a potent inhibitor of the NADPH oxidase and other flavin-containing oxidases and have been used extensively to inhibit production of ROS in plant systems (Bolwell et al. 1995). Except plasma membrane NADPH oxidase, DPI inhibits cell wall peroxidases (Ros-Barceló 1998) and respiratory chain Complex I (Fato et al. 2009). Differences in apoplastic ROS concentration in WT and MSC16 seem not to be dependent on mitochondrial ROS production since ROS production by isolated mitochondria was similar in both plants (Szal et al. 2009) also cell wall peroxidase activity was not different in WT and MSC16. Although the involvement of chloroplast and peroxisomes in ROS production cannot be ignored our previous data indicated that mitochondrial mutation in MSC16 does not significantly affect photosynthesis and photorespiration (Juszczuk et al. 2007). All together it seems that the lower $\mathrm{H}_{2} \mathrm{O}_{2}$ level detected in the apoplast of MSC16 cucumber leaves may result from the decreased NADPH oxidase activity.

In the apoplast the plasma membrane NADPH oxidase is using cytosolic NADPH as an electron donor and generates $\mathrm{O}_{2}^{-}$and subsequently $\mathrm{H}_{2} \mathrm{O}_{2}$ by the activity of SOD. We did not estimate apoplastic SOD activity but the activities of $\mathrm{Cu} / \mathrm{ZnSOD}$ isoforms 1, 2 and 3 were higher in MSC16 extracts while the activity of MnSOD was similar in both WT and MSC16 (Szal et al. 2009). NADPH oxidase-derived ROS are required during the growth of 
organs, for example during leaf expansion (Rodriguez et al. 2002). The increase in NADPH oxidase activity observed in vivo during cold treatment (Piotrovskii et al. 2011) or pathogenesis response (Neill et al. 2002) may be due to the changes in substrate (NADPH) availability or modulation by cytoplasmic factors. The mitochondrial genome rearrangement in cucumber MSC16 results in changes in respiratory chain activity, including increased activities of external NAD(P)H dehydrogenases (NDex) (Juszczuk et al. 2007). Moreover, in MSC16 plants cytosolic $\mathrm{NADP}(\mathrm{H})$ pool is lower and more oxidized than in WT (Szal et al. 2008), which in vivo may have influence on NADPH oxidase activity in MSC16. As all the measurements were performed in vitro with saturating levels of substrate, we can expect that NADPH oxidase activity in vivo may be even lower since it is dependent not only on substrate availability but also on enzyme protein level or other regulating factors like Rho-related GTPases (BaxterBurrell et al. 2002). Therefore, we suggest that the lower NADPH oxidase activity in cucumber mutants, resulting in low apoplastic ROS production, may influence MSC16 plant growth.

The total pool of foliar ascorbate (reduced plus oxidized) was about 35\% higher in MSC16 leaves than in WT leaves and the greater total abundance of ascorbate in MSC16 leaves was accompanied by a large increase in the oxidized form dehydroascorbate (DHA) (Szal et al. 2009). Cell division is sensitive to changes in apoplastic AsA, MDHA and DHA. AsA concentrations present in the cucumber leaf apoplast, which ranged in WT and MSC16 from 18 to $22 \mathrm{nM}$, respectively (Fig. 5) are comparable to the AsA levels in the apoplast of barley $(16 \mathrm{nM})$ and oat leaves (10 nM) (Vanacker et al. 1998). Total ascorbate concentration was about $14 \%$ higher in MSC16 EWF extracts and the reduced form (AsA) was substantially more abundant than in WT (Fig. 5). The apoplastic ascorbate pool of MSC16 plants was in 94\% reduced, suggesting a very efficient system of DHA translocation from the apoplast to the cytosol by a carrier-mediated AsA/DHA transport system (Horemans et al. 2000). This might explain, at least in part, why total foliar ascorbate in MSC16 plants was almost in 50\% oxidized (Szal et al. 2009).

In the apoplast of MSC16 plants AO activity was about $40 \%$ higher than in WT plants (Fig. 6). An increased AO activity leads to enhanced cell expansion in transgenic tobacco plants expressing AO in sense orientation (PAO) (Pignocchi et al. 2003). The apoplast of PAO plants also contained higher amounts of ascorbate (AsA + DHA) than the apoplast of untransformed plants (Pignocchi et al. 2003). No DHA accumulation was observed despite about $40 \%$ higher AO activity in MSC16 plants than in the apoplast of WT plants. The positive correlations between AO activities, apoplastic DHA and plant growth does not take place in MSC16 plants. It is worth saying, that oxidation of apoplastic AsA alone favours enhanced growth in transgenic tobacco overexpressing AO but does not affect cell division (Pignocchi and Foyer 2003). They also speculate that enhanced DHA accumulation could signal metabolic arrest and inhibit cell division, pointing out at least two possibilities. One of them is that DHA accumulation alone is insufficient to arrest mitosis and another possibility is that a second signal must be involved (Pignocchi and Foyer 2003). In this case it is possible to attribute the AOdependent enhancement of growth to cell elongation alone. This is exactly what takes place in MSC16 plants. The observed greater dimensions of mutant's mesophyll cells (Fig. 1) as compared with WT might be a result of enhanced cell expansion due to unsettled stiffening of the cell wall. The cell wall plays an important role in cell expansion; loosening allows cells to grow, whereas wall cross-linking can inhibit this process. There is evidence that ROS are involved in both processes (Ros-Barceló et al. 2002; Liszkay et al. 2004).

Mitochondrial genome rearrangement resulting in altered activity of ETC complexes, implies a radical alteration in whole cell redox metabolism; e.g. adenylate concentration, pyridine nucleotide redox state (Szal et al. 2008) and ROS/antioxidants homeostasis (Szal et al. 2009). Changes in the energy state of leaf cells can influence the activity of a number of specific proteins that regulate growth processes, such as NADPH oxidase and AO or other. In addition to the earlier described effects of mitochondrial mutation on MSC16 leaf carbon and energy metabolism which may affect growth (Juszczuk et al. 2007; Szal et al. 2009, 2010) our data indicate the possible involvement of apoplastic ROS in these processes.

Acknowledgments MSC16 mutant seeds were supplied by Department of Plant Genetics, Breeding and Biotechnology, Warsaw Agricultural University. This work was partially supported by the grant from the Polish Ministry of Scientific Research and Information Technology [grant number N N303 341535] given to A.M.R.. The authors are very grateful to Dr Danuta Solecka for her help with cell wall preparation.

Open Access This article is distributed under the terms of the Creative Commons Attribution Noncommercial License which permits any noncommercial use, distribution, and reproduction in any medium, provided the original author(s) and source are credited.

\section{References}

Bartoszewski G, Malepszy S, Havey MJ (2004) Mosaic (MSC) cucumber regenerated from independent cell cultures possess different mitochondrial rearrangements. Curr Genet 45:45-53

Baxter-Burrell A, Yang Z, Springer PS, Bailey-Serres J (2002) RopGAP4-dependent Rop GTPase Rheostat control of Arabidopsis oxygen deprivation tolerance. Science 269:2025-2028 
Bestwick CS, Brown IR, Bennett MHR, Mansfield JM (1997) Localization of hydrogen peroxide accumulation during the hypersensitive reaction of lettuce cells to Pseudomonas syringae pv. phaseolicola. Plant Cell 9:209-221

Bolwell GP, Butt VS, Davies DR, Zimmerlin A (1995) The origin of the oxidative burst in plants. Free Radic Res. 23:517-532

Bradford MM (1976) A rapid and sensitive method for quantification of microgram quantities of protein utilizing the principle of protein-dye binding. Anal Biochem 72:248-254

Chen Y, Gill PS, Welch WJ (2005) Oxygen availability limits renal NADPH dependent superoxide production. Am J Physiol Renal Physiol 289:F749-F573

Desican R, Burnett E, Hancock JT, Neill SJ (1998) Harpin and hydrogen peroxide induce the expression of a homologue of gp91-phox in Arabidopsis thaliana suspension cultures. J Exp Bot 49:1767-1771

Fato R, Bergamini CH, Bortolus M, Maniero AL, Leoni S, Ohnishi T, Lenaz G (2009) Differential effects of mitochondrial Complex I inhibitors on production of reactive oxygen species. Biochim Biophys Acta 1787:384-392

Foreman J, Demidchik V, Bothwell JHF, Mylona P, Miedema H, Torres MA, Linstead P, Costa S, Brownlee C, Jones JDG, Davies JM, Dolan J (2003) Reactive oxygen species produced by NADPH oxidase regulate plant cell growth. Nature 422:442-446

Foyer CH, Noctor G (2005) Oxidant and antioxidant signalling in plants: a re-evaluation of the concept of oxidative stress in a physiological context. Plant Cell Environ 28:1056-1071

Foyer CH, Noctor G (2009) Redox regulation in photosynthetic organisms: signalling, acclimation, and practical implications. Antioxid Redox Signal 11:861-905

Horemans N, Foyer CH, Asard H (2000) Transport and action of ascorbate at the plant plasma membrane. Trends Plant Sci 5:263-267

Juszczuk IM, Rychter AM (2009) BN-PAGE analysis of the respiratory chain complexes in mitochondria of cucumber MSC16 mutant. Plant Physiol Biochem 47:397-406

Juszczuk IM, Flexas J, Szal B, Dąbrowska Z, Ribas-Carbo M, Rychter AM (2007) Effect of mitochondrial genome rearrangement on respiratory activity, photosynthesis, photorespiration and energy status of MSC16 cucumber (Cucumis sativus) mutant. Physiol Plant 131:527-541

Kampfenkel K, Van Montagu M, Inzé D (1995) Extraction and determination of ascorbate and dehydroascorbate from plant tissue. Anal Biochem 225:165-167

Kato N, Esaka M (1999) Changes in ascorbate oxidase gene expression and ascorbate levels in cell division and cell elongation in tobacco cells. Physiol Plant 105:321-329

Kerk NM, Feldman LJ (1995) A biochemical model for the initiation and maintenance of the quiescent center: implications for organization of root meristems. Development 121:2825-2833

Laloi C, Apel K, Danon A (2004) Reactive oxygen signaling: latest news. Curr Opin Plant Biol 7:323-328

Lamb C, Dixon RA (1997) The oxidative burst in plant disease resistance. Annu Rev Plant Physiol Plant Mol Biol 48:251-275

Lin LS, Varner JE (1991) Expression of ascorbate oxidase in zucchini squash (Cucurbita pepo). Plant Physiol 96:159-165

Liszkay A, van der Zalm E, Schopfer P (2004) Production of reactive oxygen intermediates $\left(\mathrm{O}_{2}^{-}, \mathrm{H}_{2} \mathrm{O}_{2}\right.$, and $\left.\cdot \mathrm{OH}\right)$ by maize roots and their role in wall loosening and elongation growth. Plant Physiol 136:3114-3123

Low PS, Merida JR (1996) The oxidative burst in plant defence: function and signal transduction. Physiol Plant 96:533-542

Malepszy S, Burza W, Śmiech M (1996) Characterization of a cucumber (Cucumis sativus L.) somaclonal variation with paternal inheritance. J Appl Genet 37:65-78
Nanasato Y, Akashi K, Yokota A (2005) Co-expression of cytochrome $b_{561}$ and ascorbate oxidase in leaves of wild watermelon under drought and high light conditions. Plant Cell Physiol 46:1515-1524

Neill SJ, Desikan R, Hancock JT (2002) Hydrogen peroxide signaling. Curr Opin Plant Biol 5:388-395

Orozco-Cárdenas M, Ryan CA (1999) Hydrogen peroxide is generated systemically in plant leaves by wounding and systemin via the octadecanoid pathway. Proc Natl Acad Sci USA 96:6553-6557

Palmgren MG (1990) An $\mathrm{H}^{+}$ATPase assay: proton pumping and ATPase activity determined simultaneously in the same sample. Plant Physiol 94:882-886

Palmgren MG, Sommarin M (1989) Lysophosphatidylcholine stimulates ATP dependent proton accumulation in isolated oat root plasma membrane vesicles. Plant Physiol 90:1009-1014

Pastori GM, Kiddle G, Antoniw J, Bernard S, Veljovic-Jovanovic S, Verrier PJ, Noctor G, Foyer CH (2003) Leaf vitamin C content modulate plant defense transcripts and regulate genes that control development through hormone signaling. Plant Cell 15:939-951

Pei ZM, Murata Y, Benning G, Thomine S, Klusener B, Allen GJ, Grill E, Schroeder JI (2000) Calcium channels activated by hydrogen peroxide mediate abscisic signalling in guard cells. Nature 406:731-734

Pignocchi C, Foyer CH (2003) Apoplastic ascorbate metabolism and its role in the regulation of cell signalling. Curr Opin Plant Biol 6:379-389

Pignocchi C, Fletcher JM, Wilkinson JE, Barnes JD, Foyer CH (2003) The function of ascorbate oxidase in tobacco. Plant Physiol 132:1631-1641

Piotrovskii MS, Shevyreva TA, Zhestkova IM, Trofimova MS (2011) Activation of plasmalemmal NADPH oxidase in etiolated maize seedlings exposed to chilling temperatures. Russ J Plant Physiol $58: 234-242$

Polle A, Chakrabarti K, Schürmann W, Rennenberg H (1990) Composition and properties of hydrogen peroxide decomposing systems in extracellular and total extracts from needles of Norway spruce (Picea abies L. Karst.). Plant Physiol 94:312-319

Rodriguez AA, Grunberg KA, Taleisnik EL (2002) Reactive oxygen species in the elongation zone of maize leaves are necessary for leaf extension. Plant Physiol 129:1627-1632

Ros-Barceló A (1998) The generation of $\mathrm{H}_{2} \mathrm{O}_{2}$ in the xylem of Zinnia elegans is mediated by an NADPH-oxidase-like enzyme. Planta 207:207-216

Ros-Barceló A, Pomar F, Lopez-Serrano M, Martinez P, Pedreno MA (2002) Developmental regulation of the $\mathrm{H}_{2} \mathrm{O}_{2}$-producing system and of a basic peroxidase isoenzyme in the Zinnia elegans lignifying xylem. Plant Physiol Biochem 40:325-332

Rychter AM, Mikulska M (1990) The relationship between phosphate status and cyanide-resistant respiration in bean roots. Physiol Plant 79:663-667

Sagi M, Fluhr R (2006) Production of reactive oxygen species by plant NADPH oxidases. Plant Physiol 141:336-340

Schopfer P, Liszkay A (2006) Plasma membrane-generated reactive oxygen intermediates and their role in cell growth of plants. Bio Factors 28:73-81

Smirnoff N (2000) Ascorbate biosynthesis and function in photoprotection. Phil Trans R Soc Lond Ser B Biol Sci 355:1455-1464

Smirnoff N, Wheeler GL (2000) Ascorbic acid in plants: biosynthesis and function. Crit Rev Plant Sci 19:267-290

Solecka D, Żebrowski J, Kacperska A (2008) Are pectins involved in cold acclimation and de-acclimation of winter oil-seed rape plants? Ann Bot 101:521-530 
Szal B, Dąbrowska Z, Malmberg G, Gardeström P, Rychter AM (2008) Changes in energy status of leaf cells as the consequence of mitochondrial genome rearrangement. Planta 227: 697-706

Szal B, Łukawska K, Zdolińska I, Rychter AM (2009) Chilling stress and mitochondrial genome rearrangement in the MSC16 cucumber mutant affect the alternative oxidase and antioxidant defense system to a similar extent. Physiol Plant 137:435-445

Szal B, Jastrzębska A, Kulka M, Leśniak K, Podgórska A, Pärnik T, Ivanova H, Keerberg O, Gardeström P, Rychter AM (2010) Influence of mitochondrial genome rearrangement on cucumber leaf carbon and nitrogen metabolism. Planta 232:1371-1382

Van den Berg BM, Van Huystee RB (1984) Rapid isolation of plant peroxidase. Purification of peroxidase a from Petunia. Physiol Plant 60:299-304
Vanacker H, Carver TLW, Foyer CH (1998) Pathogen-induced changes in the antioxidant status of the apoplast in barley leaves. Plant Physiol 117:1103-1114

Wigge B, Gardeström P (1987) The effect of different ionic conditions on the activity of cytochrome $c$ oxidase in purified plant mitochondria. In: Moore AL, Beechey RB (eds) Plant mitochondria. Structural, functional, and physiological aspects. Plenum Press, New York, pp 127-130

Wojtaszek P (1997) The oxidative burst: a plant's early response against infection. Biochem J 322:681-692

Wu Y, Sharp RE, Durachko DM, Cosgrove DJ (1998) Growth maintenance of the maize primary root at low water potentials involves increases in cell-wall extension properties, expansin activity, and wall susceptibility to expansions. Plant Physiol 111:765-772 